\title{
CONFERENCIA
}

\section{RAZA, GENES Y CULTURA}

\section{Ulrich Kattmann ${ }^{1}$}

\section{Resumen}

El concepto de raza no tiene bases genéticas, los patrones de ADN y genéticos no están confinados por los límites continentales y no concuerdan con ninguna clasificación de las llamadas razas. Los genes que determinan rasgos de apariencia son solo un pequeño subconjunto de todos los genes humanos. Además, la apariencia no muestra similitud genética o parentesco entre grupos humanos. Esta clasificación es un recurso fundamental del racismo, y el culturalismo emerge directamente del racismo y lo imita. Las concepciones raciales asumen que los grupos humanos se han desarrollado de forma aislada y sobreviven en el reclamo de culturas completamente diferentes y hostiles, lo que ha sido recientemente expresado como "choque de civilizaciones", un renacimiento de la "kulturkreislehre" del siglo XIX. Un elemento fundamental del racismo y del culturalismo es la generalización y esta suele convertirse en una trampa de la simplificación. Las claves para superar el pensamiento racista y culturalista se centran en el individuo, de este modo se podrá abolir el pensamiento tipológico y reconocer el carácter especial de la diversidad humana.

Palabras clave: raza, cultura, racismo.

\section{Abstract}

\section{Conference. Genes, race and culture}

The concept of race has no genetic basis, DNA and genetic patterns are not confined by continental boundaries and do not agree with any classification of so-called races. The genes that determine appearance traits are only a small subset of all human genes. Furthermore, appearance shows no genetic similarity or kinship between human groups. This classification is a fundamental resource of racism, and culturalism emerges directly from racism and imitates it. Racial conceptions assume that human groups have developed in isolation and survive in the grip of completely different and hostile cultures, which has recently been expressed as a "clash of civilizations", a renaissance of the 19th century "kulturkreislehre". A fundamental element of racism and culturalism is generalization, and this often becomes a trap of simplification. The keys to overcoming racist and culturalist thinking are centered on the individual, in this way typological thinking could be abolished and the special character of human diversity recognized.

Keywords: race, culture, racism.

Ulrich Kattmann: Biólogo alemán y profesor de la Carl von Ossietzky Universität Oldenburg. Activo en las áreas de la antropología y la investigación didáctica.

Email: ulrich.kattmann@uni-oldenburg.de

1 Traducido del original: Kattmann, U. (2013). Genes, Race and Culture. En M. Koegeler-Abdi y R. Parncutt (eds.) (2013). Interculturality: Practice meets Research. Cambridge: Cambridge Scholars Publishing. Traducción de Daniel Mateo Ordóñez, sociólogo de la Universidad Nacional de Colombia, febrero de 2020. 


\section{La realidad científica de las razas}

\section{Color como estereotipo racial}

Ninguna otra característica ha sido tan estrechamente vinculada al concepto de raza como el color de la piel. Para los antropólogos, sin embargo, la pigmentación de la piel para clasificar humanos es inútil. La pigmentación de la piel humana varía continuamente con la latitud geográfica, con pequeñas discontinuidades y excepciones. Esta distribución es causada principalmente por selección debido a la radiación UV. Como resultado, poblaciones humanas de la misma latitud generalmente muestran el mismo grado de pigmentación de la piel, por ejemplo, personas de piel oscura alrededor de la línea ecuatorial en África, Asia, Australia y América del Sur. La distribución de la pigmentación es el resultado paralelo de la evolución convergente, no de descendencia común. Por lo tanto, el "color" no dice nada sobre el parentesco entre seres humanos.

Sin embargo, las concepciones raciales están dominadas por "colores", como la oposición "blancos" y "negros" o "blancos" y "de color". Los europeos se entienden a sí mismos como "blancos", a pesar del hecho de que las pigmentaciones de los europeos del sur y las de la mayoría de los asiáticos (los cuales son llamados "amarillos") son casi idénticas. La discriminación entre "negros", "blancos", "amarillos" y "rojos" es parte de la doctrina racial del color, utilizada para indicar diferencias esenciales que no existen en absoluto. Siguiendo estas discriminaciones raciales, la cultura europea sirve como evidencia de la preeminencia o privilegio del "hombre blanco".

\section{La idea del aislamiento}

Tradicionalmente, en la ciencia se piensa que las diferencias entre poblaciones humanas y culturas son causadas por la evolución a través del aislamiento y la selección. Fue reclamado que las razas humanas se originaron por separado en áreas aisladas (llamadas áreas de selección, "züchtungsräume"). Esta concepción iba en línea con el concepto de evolución en la biología convencional. La idea de aislamiento no solo dominó la biología evolutiva durante mucho tiempo, también fue adoptada en otras disciplinas, que influenciaron el pensamiento racial y las interpretaciones raciales de las culturas humanas (Tabla 1). 
La idea de aislamiento dio también nacimiento a la idea etnológica de "kulturkreise", del joven Leo Frobenius (1873-1938), retomada en la concepción de "civilizaciones principales" en El choque de civilizaciones y la reconfiguración del orden mundial, de Samuel Huntington, en 1996. Con respecto a este entendimiento y la atribución de las culturas a "pseudoespecies" (Erikson y Stjernfelt, 2009), debe ser señalado que las culturas no están aisladas; no están cercanas las unas de las otras, pero viven a través del intercambio de materias e ideas. Lo mismo es verdad para las "razas": las poblaciones humanas no evolucionaron de forma aislada, sino en un frecuente y sostenido intercambio genético y cultural a través de la migración.

Tabla 1. Aislamiento como idea científica

\begin{tabular}{|c|c|}
\hline Disciplina & Concepciones \\
\hline $\begin{array}{l}\text { Filosofía de la historia } \\
\text { Gobineau (1860-1882) y } \\
\text { seguidores }\end{array}$ & $\begin{array}{l}\text { Teoría de la cultura: culturas superiores son creadas y } \\
\text { conducidas por razas superiores. } \\
\text { Degeneración de la cultura por la mezcla de razas. }\end{array}$ \\
\hline $\begin{array}{l}\text { Biología evolutiva } \\
\text { Psicología } \\
\text { Erik Erikson [1902-1994] } \\
\text { Estudios culturales }\end{array}$ & $\begin{array}{l}\text { Origen de las razas y especiación por separación geográfica. } \\
\text { Origen de las diferentes culturas por distribución y alienación } \\
\text { para lograr "identidad". Para enfatizar la diversificación de } \\
\text { las culturas, son definidas como entidades aisladas y -en } \\
\text { analogía con la diversidad de las especies animales— llamadas } \\
\text { "pseudoespecies". } \\
\text { Pensando en culturas solo en plural: destacando diferencias y } \\
\text { animosidades entre culturas, las culturas son tratadas como } \\
\text { entidades autocontenidas. }\end{array}$ \\
\hline Antropología biológica & $\begin{array}{l}\text { Origen de razas humanas por selección natural en aislamiento } \\
\text { geográfico. "Razas" como precursoras evolucionarias de las } \\
\text { verdaderas especies. } \\
\text { Las culturas son productos de rasgos raciales: vinculación de } \\
\text { una "cultura superior" a "razas superiores". }\end{array}$ \\
\hline
\end{tabular}

Fuente: Elaboración propia.

\section{Estudios genéticos sobre raza}

Hasta ahora, la biología se refiere a la definición de raza basada en las diferencias genéticas. Esas diferencias están conectadas a diferencias en las secuencias de ADN. Pueden ocurrir dentro de los genes o en partes silenciosas del ADN que no se traducen en productos genéticos (como ARN y proteínas).

Diferentes secuencias de ADN o versiones de genes que están localizadas en el mismo lugar que un cromosoma (locus del gen) son llamadas genes alélicos o alelos. De manera sintética, los alelos son genes (o, más general, secuencias de ADN) del mismo gen locus. Un individuo humano tiene dos 
conjuntos de cromosomas en su núcleo celular y, en consecuencia, dos alelos diferentes o dos idénticos.

Para dar un ejemplo: en el cromosoma n. ${ }^{\circ} 7$ del genoma humano está el gen locus referido a la producción de una proteína específica de la membrana celular. Esta proteína normalmente regula el consumo de iones de cloruro dentro de la célula. Si el gen relacionado muta, el consumo de iones de cloruro es inhibido. El gen mutado y el gen original están localizados en el mismo gen locus de los cromosomas.$^{\circ} 7$, por lo tanto, son alelos. Si un individuo tiene el gen mutado en ambos de sus cromosomas n. ${ }^{\circ} 7$, la combinación de dos alelos mutados puede llevar a la enfermedad de fibrosis quística. La fibrosis quística es la enfermedad genéticamente determinada más frecuente en Europa occidental. En otras partes del continente, el alelo mutado es menos frecuente. Así, las frecuencias de los dos alelos hacen parte de las diferencias genéticas entre poblaciones europeas.

Este resultado puede ser generalizado: las diferencias genéticas entre poblaciones humanas son siempre diferencias en las frecuencias de los alelos. Los antropólogos están acostumbrados a hablar convencionalmente de genes, cuando en realidad se refieren a alelos. Para ser claro, a continuación, en lugar del término gen, se usa el término alelo en la definición dada (también en expresiones o palabras combinadas, por ejemplo, "flujo de gen").

Antes, los genetistas pensaban que todos los individuos de la misma raza podían tener ciertos alelos en común, ausentes en los individuos de otra raza. Pero en la naturaleza las diferencias genéticas entre poblaciones son solo estadísticas. Por lo tanto, la comunidad genetista definió a las razas como poblaciones (de las mismas especies), lo que difiere en la frecuencia de sus alelos (Dunn y Dobhansky, 1946). De manera implícita, esta definición incluye la suposición de que —en términos genéticos- individuos pertenecientes a una raza difieren esencialmente de individuos de otra raza. Pero la genética molecular muestra de manera bastante clara que esto no es verdad para la diversidad de las poblaciones humanas.

Los elementos más importantes para la comprensión de la diversidad humana son: mayor diversidad dentro de una misma población humana, no entre poblaciones, constante variación en las frecuencias de los alelos en todo el mundo y la sorprendente similitud genética de todos los humanos.

En consecuencia, un grupo de expertos señala:

"La revolución en nuestro pensamiento sobre la genética de poblaciones y la biología molecular ha conducido a una explosión de conocimiento de los organismos vivos. Entre las ideas que han sido profundamente alteradas hay conceptos de variación humana. El concepto de 'raza' traído del pasado hasta el siglo XX se ha vuelto completamente obsoleto... No hay razón científica para continuar usando el término 'raza'." (UNESCO, 1995). 
Cuando se analizan poblaciones de diferentes regiones geográficas, el resultado más llamativo es que la mayoría de las diferencias se encuentra dentro de una misma población, no entre ellas. El análisis molecular de la frecuencia de los alelos ha mostrado que, dentro de cualquier grupo de humanos, las diferencias entre individuos son grandes en comparación con las diferencias entre grupos, que son comparativamente pequeñas. Las diferencias entre poblaciones de diferentes continentes (normalmente asociadas con "razas" geográficas) contribuyen a solo un $10 \%$ de la variación general de los humanos (Figura 1). Como consecuencia, el significado de la clasificación racial se desvanece: para cada "blanco" europeo se puede encontrar un "negro" africano que es genéticamente más similar a él que su vecino de piel más clara.

Sin embargo, series de estudios en variación genética parecen apoyar la clasificación tradicional en "razas" geográficas. Estos encuentran grupos de similitud genética que corresponden a la distribución geográfica de las poblaciones. El estudio más voluminoso con este tipo de resultados (Jorde, et al., 1997) fue reanalizado, cuestionando el muestreo (Serre y Pääbo, 2004). Los participantes del estudio eran originarios de regiones localizadas en los bordes del continente, es decir, se reunieron datos solo de grupos que frecuentemente migraban a Estados Unidos. Si el muestreo incluyese los continentes enteros, los grupos continentales - usando las mismas estadísticas - desaparecerían. Por lo tanto, son artefactos del conveniente muestreo estadounidense.

Los autores del reanálisis concluyeron:

"Hay una gran tendencia en la literatura a usar unas cuantas poblaciones de los extremos de las masas de tierra continentales..., a hacer inferencias en todo el mundo sobre las subestructuras en el acervo genético humano. De hecho, por la genética humana, la diversidad tiende a distribuirse continuamente, lo cual es especialmente problemático para muestrear los extremos de los continentes, porque esto crearía la impresión de agudas discontinuidades en las variantes genéticas. Al respecto, no sirve de nada que la historia de la colonización de los Estados Unidos haya resultado en un 'muestreo' de la población humana conformada en gran parte por personas de Europa occidental, África occidental y el sudeste asiático. Así, los estudios en los cuales individuos de Europa, el África subsahariana y el sudeste asiático son usados (por ejemplo Jorde, et al., 1997) podrían ser una descripción adecuada de la mayoría de los componentes de la población estadounidense... Sin embargo, sería incorrecto concluir que dichos estudios necesariamente generalizan a subdivisiones del acervo genético humano a escala mundial.” (Serre y Pääbo, 2004, p. 1683). 
Figura 1. Diferencias genéticas dentro y entre grupos de diferente origen geográfico. Genes variables: dos o más alelos son conocidos (Lewontin, 1972;

Excoffier y Hamilton, 2003]
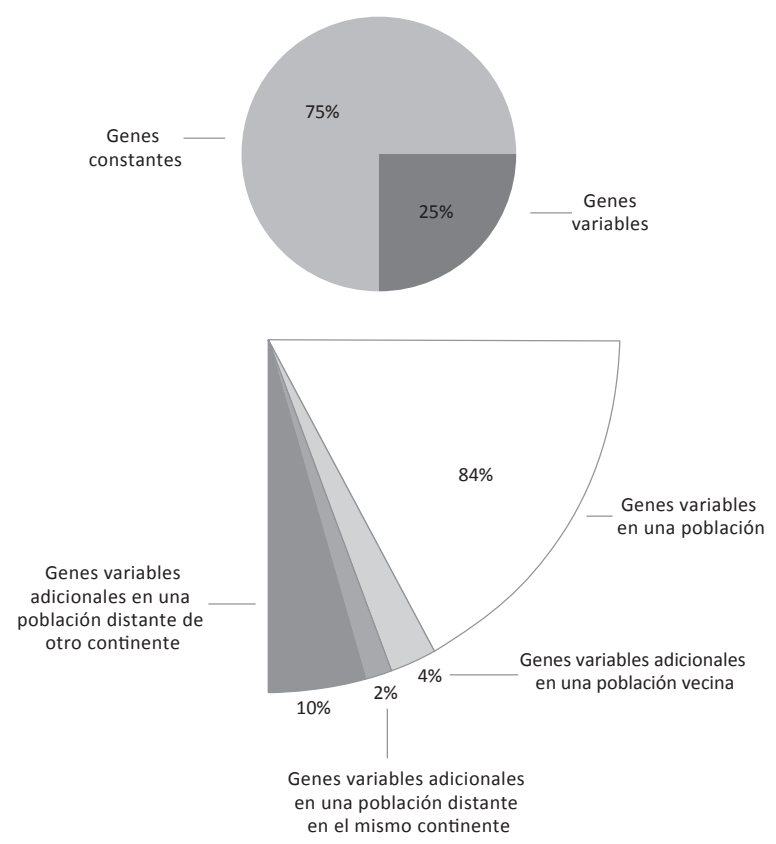

Fuente: Elaboración propia.

Debido a las extremas migraciones durante cerca de 100.000 años, los continentes no formaron barreras para el flujo del alelo entre poblaciones humanas. De acuerdo con esto, los patrones genéticos no están restringidos a un continente, sino distribuidos entre ellos, documentando así la historia migratoria humana.

Grandes monos de la misma especie, pero con orígenes geográficos diferentes, no pueden ser distinguidos fácilmente por una persona común, si bien esto no es un problema de los humanos. Sin embargo, las distancias genéticas entre humanos son asombrosamente cortas: mientras el patrón de derivación en poblaciones de chimpancés se asemeja a un gran arbusto, en el caso de los humanos las pequeñas ramas están estrechamente unidas. Se podría hablar de un patrón de "cepillo de botella" (Figura 2). 
Figura 2. Distancias genéticas (vecino próximo) del ADN mitocondrial (región de control 1) entre individuos de poblaciones de los grandes simios y Homo sapiens [Gagneux et al., 1999]

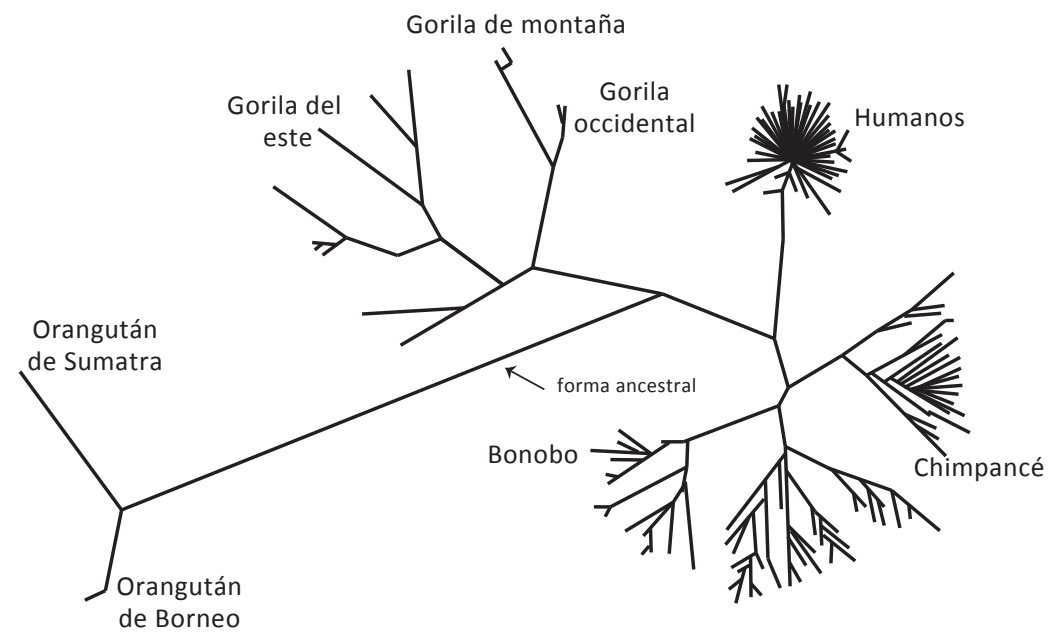

Fuente: Elaboración propia.

La frecuencia de alelos de cada población de humanos es estadísticamente diferente de la de otras. Esto es verdad, por ejemplo, para austriacos y alemanes e incluso para los habitantes de dos ciudades vecinas. Las diferencias aumentan con la distancia geográfica. Pero incluso estas diferencias no tienen gran importancia y no justifican la clasificación en distintas razas (como en el caso de los austriacos y alemanes).

La migración del Homo sapiens se inició en África unos noventa mil años atrás y ha pasado por diferentes cuellos de botella que redujeron la diversidad de forma decisiva. Este desarrollo fue seguido por un rápido crecimiento de la población. Ahora somos una población global con la diversidad genética de un grupo de diez mil africanos que migraron, se establecieron en todo el globo y se convirtieron en siete mil millones: todos somos africanos.

En resumen, el concepto de raza no tiene bases genéticas, los patrones de ADN no están distribuidos a lo largo de las fronteras ficticias de los continentes y no tienen correlación con cualquiera de las categorías llamadas razas (Cavalli-Sforza, Menozzi y Piazza, 1996; Cavalli-Sforza, 1997; Templeton, 1999; Pääbo, 2001; Royal y Dunston, 2004; Serre y Pääbo, 2004; Stix, 2008). 


\section{Racismo y culturalismo}

\section{Pasos hacia el racismo}

A pesar de los resultados de los estudios genéticos, los racistas crean su punto de vista de las razas sobre la base de sus propios intereses. Incluso para las personas bien intencionadas, el conocimiento de que el concepto biológico de raza es científicamente obsoleto no es suficiente para superar los prejuicios o las actitudes racistas (Janßen, 1998). Pero la percepción de la formación del pensamiento y las acciones racistas puede ayudar a identificarlos y evidenciarlos. En los pasos hacia el racismo, el concepto de raza juega un rol importante. Explícita o implícitamente, este concepto está casi inevitablemente asociado al prejuicio racial. La imagen de los extraños emerge de la imagen propia: la autoimagen positiva de un grupo crea la imagen negativa de fuera del grupo - esto ocurre, por ejemplo, con el estereotipo hetero (Nolting, 1987; Kattmann, 1997)—. Por esto, las imágenes de fuera del grupo (estereotipos y prejuicios raciales, sexuales y culturales) no encajan en la realidad: ellas no nos dicen nada sobre las características de fuera del grupo (y, naturalmente, tampoco del grupo) (Kattmann, 1980).

La clasificación de razas en la biología (incluyendo enfoques históricos) y la discriminación racial pueden ser caracterizadas a través de procesos muy similares (Tabla 2). Tal como lo describe la psicología social, los paralelos entre los mecanismos de la discriminación de grupo y el proceso de clasificación de las razas son llamativos y demuestran que, biológicamente, las razas son construcciones sociales. Esto también se muestra por el hecho de que las clasificaciones raciales difieren en extremo entre culturas y grupos sociales debido a fuertes influencias de intereses sociales de los grupos clasificadores (Kattmann, 1999).

La clasificación de humanos en razas es de por sí un recurso fundamental del racismo, que promueve la discriminación social y culmina en el crimen de genocidio (Tabla 3). Si se conecta con la valoración social, la clasificación da a luz consecuencias peligrosas. Esto es verdad para las ideologías de superioridad de "blancos" sobre "negros" o de "cultura" sobre "razas primitivas". 
Tabla 2. Paralelos entre la formación de los prejuicios raciales y la clasificación biológica de las razas

\begin{tabular}{|c|c|}
\hline $\begin{array}{l}\text { Formación de prejuicios raciales [descrita por la } \\
\text { psicología social] }\end{array}$ & Doctrinas raciales [en la ciencia] \\
\hline $\begin{array}{l}\text { Conciencia de la afiliación a un grupo } \\
\text { Formación culturalmente determinada de grupos }\end{array}$ & $\begin{array}{l}\text { Muestreo de rasgos raciales típicos } \\
\text { Clasificaciones raciales divergentes }\end{array}$ \\
\hline Distribución y alienación de grupos & $\begin{array}{l}\text { Conceptos y definiciones de "raza" } \\
\text { Ideas esencialistas de la raza como } \\
\text { unidades persistentes de evolución }\end{array}$ \\
\hline $\begin{array}{c}\text { Evaluación de grupos } \\
\text { La autoimagen determina la imagen de fuera del } \\
\text { grupo }\end{array}$ & $\begin{array}{l}\text { Enlace de "raza" con habilidades } \\
\text { mentales y culturales } \\
\text { Inferioridad de las razas extranjeras }\end{array}$ \\
\hline $\begin{array}{l}\text { Ideología de grupo causada por conflictos e } \\
\text { intereses sociales }\end{array}$ & $\begin{array}{c}\text { Construcción social de la raza } \\
\text { Dicotomías "blancos" y "negros", "arios" } \\
\text { y "judíos" }\end{array}$ \\
\hline
\end{tabular}

Fuente: Elaboración propia.

Históricamente, la conexión entre la clasificación biológica de las razas y el racismo es bastante fuerte. El ejemplo más llamativo es el de la colaboración de antropólogos físicos alemanes con los nacionalsocialistas para conducir las "leyes raciales". Con las Leyes de Nuremberg de 1935 los judíos perdieron sus derechos como ciudadanos alemanes y los matrimonios entre judíos y personas de "sangre alemana y afín" fueron prohibidos. En los casos de incertidumbre de la paternidad, estas leyes prescribían la tarea de identificar si una persona era "judía", "híbrido" o "alemán o de sangre afín". Miembros de institutos de antropología de universidades reclamaron que ellos eran los únicos expertos capaces de determinar la "raza" de una persona. En general, estos "expertos" decidieron inescrupulosamente que las personas con menos estudios eran judíos, sin considerar los asesinatos que los esperaban en los campos de concentración (Seidler y Rett, 1982).

Cabe destacar que la división de grupos, y no su evaluación, es el primer paso del racismo. La cohesión entre los niveles de racismo y sus consecuencias deben ser admitidas y evidenciadas en la investigación y práctica cultural. Además, los mismos niveles aplican al culturalismo. 
Tabla 3. Diferentes clases de racismo y sus consecuencias para la vida humana

\begin{tabular}{cc}
\hline Enfoques del racismo & Estrategias de los racistas \\
\hline $\begin{array}{c}\text { Pureza } \\
\text { Las razas difieren en su esencia; las razas deben } \\
\text { mantenerse puras. }\end{array}$ & Segregación, apartheid, guetos \\
\hline $\begin{array}{c}\text { Superioridad } \\
\text { Las razas difieren en valor: "mi raza es la mejor". }\end{array}$ & $\begin{array}{c}\text { Discriminación social, supresión } \\
\text { política }\end{array}$ \\
\hline $\begin{array}{c}\text { Selección } \\
\text { Las razas deben ser constantemente mejoradas o se } \\
\text { degenerán. }\end{array}$ & $\begin{array}{c}\text { Programas de esterilización, } \\
\text { eugenesia }\end{array}$ \\
Mi raza debe ser mejorada por selección positiva y \\
protegida de otras razas por selección negativa. \\
Limpieza \\
Los extraños son una amenaza, deben ser eliminados de \\
mi territorio.
\end{tabular}

Fuente: Elaboración propia.

\section{Raíces del culturalismo}

"El culturalismo es la idea de que los individuos están determinados por su cultura, que esas culturas se forman de manera cerrada, totalmente orgánicas y que el individuo es incapaz de dejar su propia cultura, y, más bien, que solo puede realizarse a sí mismo dentro de ella. El culturalismo también mantiene que las culturas tienen derecho a derechos y protecciones especiales, incluso si al mismo tiempo ellos violan derechos individuales." (Erikson y Stjernfelt, 2009, p. 1).

El culturalismo se basa principalmente en una visión disruptiva de que las culturas humanas son esencialmente diversas. La diversidad de las culturas (no su unicidad) era el problema dominante de la etnología. Así, la antropología se enfocó en las razas como unidades esenciales y no en las especies humanas como un todo. Las razas no estaban definidas solamente por los rasgos del cuerpo, también por características psicológicas y culturales. En el siglo XVIII, el conde francés Arthur de Gobineau (18161882) construyó una filosofía de la historia que reclamaba que la cultura europea había sido fundada y se basaba en la raza "nórdica", "aria" o "germana", y que, inevitablemente, la mezcla de razas destruirá a la cultura. Esto fue sostenido por Gobineau y varios de sus seguidores en los siglos XIX y XX (por ejemplo, Houston Steward Chamberlain, 1855-1927, quien fue leído con impaciencia por Adolf Hitler). Algunos elementos de este tipo de pensamiento todavía son virulentos. Siguiendo las huellas de Gobineau, un antropólogo alemán, formador de gran influencia, considera que la cultura 
depende de la raza: "Cada cultura autóctona debe originalmente crecer en el suelo de las habilidades especiales y aptitudes de los humanos que la están llevando" (Knußmann, 1996, p. 426).

La afinidad del culturalismo con el racismo debe ser reconocida en los estudios culturales: en la definición citada, la separación de culturas (como el desarrollo aislado de las razas) y su tratamiento como entidades que determinan al individuo no son paralelos superficiales, sino los resultados de la concepción histórica de que raza y cultura están estrechamente vinculadas entre sí. La idea de aislamiento, y aún más la concepción de un antagonismo hostil, permanece de manera virulenta tanto en el racismo como en el culturalismo. Esta reciente ideología alcanzó su expresión más influyente en el postulado "choque de civilizaciones", destacando principalmente la confrontación de los "occidentales" con el mundo islámico (Huntington, 1996).

\section{Trampas de la simplicidad}

La generalización y los esquemas sirven fundamentalmente como herramientas de orientación en un mundo complejo y diversificado. Pero las generalizaciones también son peligrosas. De manera inevitable, las generalizaciones están conectadas con pérdidas de información: la individualidad se pierde en el promedio. Si esta circunstancia no se evidencia, los resultados de la generalización se vuelven trampas de la simplificación. La simplicidad, entonces, evoca la reificación de tipos abstractos, tales como "razas humanas", "niveles de cultura", "rol de los sexos", y puede estar vinculada con estereotipos racistas, culturalistas o sexistas. Explícita o implícitamente, las valoraciones favorecen el desarrollo de ideologías como el racismo, el sexismo o el culturalismo. Los medios de la simplificación son: tipos, dicotomías y valores medios.

- Los tipos son imágenes ideales o tipos derivados estadísticamente (clases), que desplazan la diversidad de los individuos. La formación de los tipos está basada en el concepto de que individuos con similares características deben ser estandarizados, ubicándolos en una clase unificadora. Una forma más débil es la orientación a través de prototipos (Rosch, et al., 1976). Si son tipos de razas, culturas o sexos, existen solo en nuestras mentes. En biología, la formación de tipos es en especial inadecuada porque la variabilidad, difusión y continuidad de las características en grupos y entre grupos se da de manera descuidada. En biología, los tipos son solo instrumentos que ayudan a describir taxones y a reconstruir la historia de grupos filogenéticos. En etnología, los tipos de culturas son útiles para ordenar y tener una visión general de la diversidad de la vida humana. 
Pero la cultura debe ser comprendida como entidad y como proceso evolutivo en la historia de los humanos, por lo que el cambio y la mutabilidad deben ser considerados. Las regularidades, las leyes y, al menos, los llamados principios de conservación (conservación de las especies o "razas" o cultura) no pueden ser deducidos de los tipos.

- Las dicotomías dividen la diversidad de procesos y modos de vida en alternativas en apariencia incompatibles. Luego, formas intermedias y la continuidad evolutiva e histórica son descuidadas o tratadas como marginales. Esto es cierto para la dicotomía de los sexos, en la que la superposición de características y, aún más serio, los intersexuales son excluidos. Esto también aplica a las políticamente motivadas dicotomías racistas de "blancos" y "negros" o "de color" y "blancos" y a la distinción entre las llamadas civilizaciones primitivas y las altas civilizaciones.

- La formación de valores medios también es un instrumento para reducir la diversidad a la simplicidad y obtener tipos homogéneos. De este modo, la difusión de características es ignorada. Una vez formada y estadísticamente salvada por la importancia, la pérdida de información a menudo no se tiene en cuenta, pero en general es seguida de suposiciones científicas de largo alcance (por ejemplo deducir la habilidad de los grupos a partir de los valores del coeficiente intelectual).

Las trampas de la simplicidad no son la causa última de tales valoraciones sociales, pero tienden a fortalecerlas. Se debe tener cuidado, ya que las tendencias habituales del pensamiento conducen a generalizaciones, tipos y dicotomías que son efectivos instrumentos mentales para justificar y hacer cumplir intereses motivados personal o socialmente. Por consiguiente, las cuestiones de medidas educativas no son solo valoraciones y discriminación social por sí mismas, sino medidas de formación y uso adecuado del conocimiento.

\section{Más allá de las razas y el choque de civilizaciones}

\section{Solo la cultura humana}

Para prevenir el racismo y el culturalismo no es suficiente con negar la existencia de las razas o enfatizar las similitudes culturales. Uno tiene que explicar las diferencias entre culturas que, en el marco de estos enfoques, están vinculadas a las diferentes habilidades mentales de las poblaciones o "razas". Por esto, es de gran importancia ofrecer una explicación alternativa. De acuerdo con Jared Diamond (1997), las condiciones biogeográficas hacen 
la diferencia: la agricultura, y, como consecuencia, la civilización compleja, emergió en áreas habitadas por plantas y animales apropiados para la domesticación. Estos datos deben ser usados para pintar una imagen correcta del desarrollo de las poblaciones y culturas humanas (Kattmann, 2009).

Además, las diferentes culturas no deben ser tratadas como alternativas excluyentes, sino que debe enfatizarse que son componentes complementarios de la cultura humana. En la visión biológica inclusiva, la cultura es un rasgo específico de la especie humana (Homo sapiens). Por lo tanto, el concepto de cultura debería ser entendido principalmente como una unidad y, por consiguiente, debería ser usado en singular. Se debe promover un pensamiento inclusivo que busque combinar opuestos en un todo (Schaefer, 1984) y mostrar que las variedades culturales son solo facetas de la cultura como una característica humana única y universal. Este punto de vista inclusivo puede ser un instrumento efectivo contra el pensamiento racista y culturalista que aplica dicotomías y características grupales disruptivas: las diferencias no son negadas o supervisadas, sino que son valoradas como una pluralidad dentro de la unidad fundamental de la cultura humana. Los puntos en común ya no son vistos como accidentales, sino como esenciales. De este modo, las diferencias pierden su poder separador, y a veces hostil, y pueden convertirse en puntos de partida hacia el diseño de una existencia enriquecida.

Los estudios calificados como interculturales o transculturales —o, más abiertamente, la afirmación del desarrollo multicultural - aún implican la existencia de culturas separadas y por esto respaldan el pensamiento disruptivo del culturalismo. En este sentido, los estudios en los cuales la cultura humana es el problema deberían, de manera adecuada, ser simplemente llamados investigación cultural.

\section{Interpretación de las curvas de campana}

La superposición de distribuciones normales (curvas de campana) puede ayudar a entender la diversidad humana (Figura 3). La zona de superposición es vista de forma espontánea en el área aproximadamente triangular entre las dos curvas (superposición de fantasía). Esta percepción de una superposición de lugares enfatiza en las diferencias grupales y hace creer que los grupos tienen solo unos cuantos valores en común. Pero la verdadera zona de superposición es el área donde las dos curvas tienen los mismos valores en común en el eje X. Esta zona de superposición casi siempre incluye los valores medios de ambos grupos. Por consiguiente, los valores medios no nos dicen nada sobre los individuos de los dos grupos (es decir, "razas" o cualquier otra división con un patrón de distribución similar). 


\section{Figura 3. Superposición de curvas de campana de dos grupos o poblaciones}

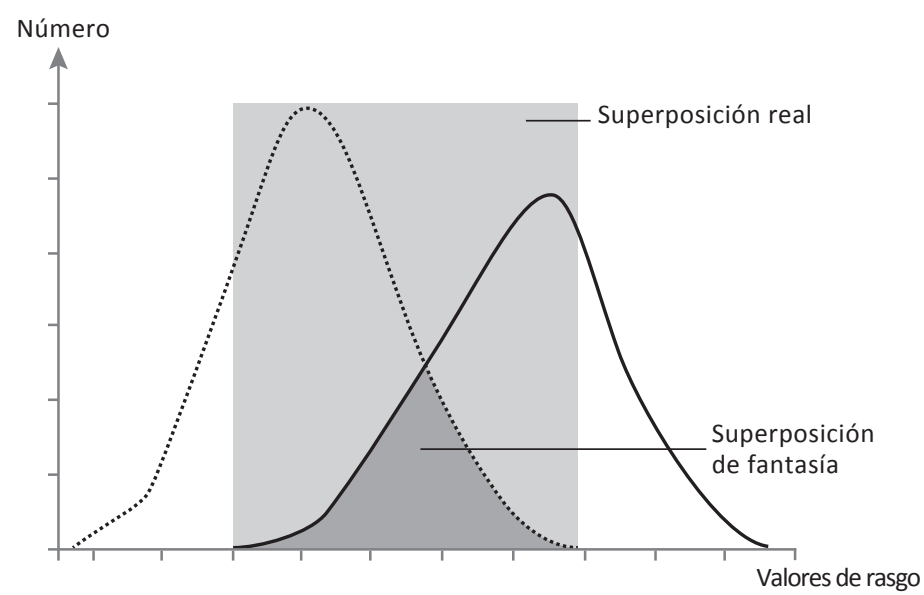

Fuente: Elaboración propia.

\section{Centrarse en el individuo}

Actualmente, la concepción de "raza" parece revivir con respecto a algunas enfermedades genéticas y su terapia. En Estados Unidos, la anemia de células falciformes es llamada "enfermedad negra", ya que los casos de esta enfermedad son encontrados frecuentemente entre afroamericanos. Las engañosas y peligrosas consecuencias de tal reificación de la raza pueden ser demostradas con el caso de un pequeño niño pobre, malinterpretado por sus doctores debido al color claro de su piel.

"Como en el siguiente ejemplo, etiquetar esta enfermedad sobre la base del fenotipo (color de piel) resultó en consecuencias serias para la salud de individuos que no son fenotípicamente 'negros' pero tienen las variantes genéticas relevantes. Un niño de 8 años, fenotípicamente europeo, fue presentado con dolor abdominal agudo y anemia (hematocrito 0,21). A pesar de que su temperatura corporal era de $37,9^{\circ} \mathrm{C}$, la cirugía fue considerada. Un técnico (accidentalmente) encontró corpúsculos rojos con características hematolíticas en un frotis. La cirugía fue cancelada luego de que los resultados de una prueba para anemia falciforme salieran positivos, y el niño fue tratado por anemia falciforme no diagnosticada previamente. Sus padres eran de Granada y tenían ancestros de la India, norte de Europa y del Mediterráneo. Este caso destaca la idea de que la ascendencia es un mejor indicador que la 'raza' o la 'etnia' si uno lleva los marcadores de anemia falciforme.” (Rotimi, 2004, p. 45). 
Ya que los muestreos están orientados hacia la "raza", un científico líder propone la siguiente declaración para que sea incluida en cada estudio sobre poblaciones humanas: "Las frecuencias de los alelos varían entre cualquier grupo humano seleccionado, asumir que esas variaciones reflejan "categorías raciales' no tiene justificación" (Duster, 2005, p. 1051). Esto también puede ser un recordatorio en los estudios culturales. El punto más importante para evitar el pensamiento racista, sexista y culturalista es enfocarse en el individuo. La imagen del individuo no debe ser oscurecida por el estereotipo de las llamadas características típicas del grupo al que el individuo pertenece. Dichas categorizaciones pueden siempre ser dañinas para individuos que no se ajustan al etiquetado racial o cultural.

El intento por centrarse en el individuo debe asegurarse en tres pasos:

- Tener cuidado con la tendencia general a reducir la complejidad y a pasar por alto la individualidad mediante la formación de tipos.

- Reconocer que los esfuerzos mentales para discriminar fuera del grupo son medios para mantener la autoimagen (tener en cuenta que formar una imagen propia crea la imagen extraña).

- Considerar los propios (y profundos) intereses personales, sociales o políticos y prejuicios y no permitir que estos guíen nuestros pensamientos o acciones

El efecto de centrarse en el individuo y las consecuencias opuestas de la orientación en imágenes grupales puede demostrarse en dos pequeñas historias que aprendí de las personas involucradas:

"La enfermera trajo un niño nuevo al grupo del jardín de infantes. Una niña pequeña señaló al niño de piel oscura y gritó: ' $¡ O h$, miren, un negro!'. Consciente de la situación, la enfermera le dijo al grupo: 'Él no es un negro, él es Gordon'."

"Yo era un buen amigo de Elly. Repentinamente, Elly no apareció en la escuela. La profesora dijo a la clase que Elly había tenido que dejar la escuela. Cuando le dije a mi madre que estaba muy triste por que Elly estaba ausente y que no sabía por qué había abandonado la escuela, mi madre me dijo: 'Elly es judía, tú sabes'."

La historia de Gordon sucedió en un jardín de infantes en Kiel (Alemania) hace varios años. Luego de la intervención de la enfermera, centrándose en el individuo, el niño fue totalmente aceptado por el grupo. La historia de Elly sucedió en la Alemania nazi. Me fue contada por una mujer anciana, quien expresó sus sentimientos: "Es extraño, hoy en día no puedo entender por qué me sentí satisfecha con esa respuesta y no pregunté de nuevo". Pero su reacción es bastante comprensible: la fijación a las diferencias del grupo bloqueó la reflexión y las preguntas. 


\section{Recomendaciones para aplicar la investigación cultural}

- Los conceptos biológicos de raza deben ser considerados como completamente obsoletos.

- Evidenciando el hecho de que la raza no tiene bases genéticas, la cuestión más importante no es si las razas existen o no, sino si los conceptos biológicos de raza son adecuados para la diversidad gradual de los humanos.

- Mientras que los biólogos deberían abandonar el concepto de raza, los psicólogos y científicos culturales no pueden olvidar la "raza".

- La "raza" es (incluso en la ciencia) un constructo social con consecuencias atroces para la vida humana.

- Después de abandonar el concepto biológico de raza, es necesario ser conscientes del racismo basado en la biología y la cultura.

- Los racistas (y otros) crean "razas" por sus creencias.

- La comprensión de la diversidad de las culturas debe ser enmarcada en la percepción de que solo existe una cultura humana y, de este modo, el disruptivo e incluso hostil culturalismo debe ser abandonado.

- Si aparecen concepciones o creencias raciales, sexistas o culturalistas, es necesario centrarse en el individuo.

Las claves para superar el pensamiento racial, sexista y culturalista yacen en:

- La percepción de los individuos como objetos concretos, mientras que los tipos son simplemente abstractos crudos.

- La ambigüedad duradera, los puntos en común y la superposición de aparentemente opuestos excluyentes.

- La consciencia de la variación y la reflexión del significado de distribución normal.

Las connotaciones de la "raza" y el racismo, así como del culturalismo, deben convertirse en problemáticas de discusión, educación y meditación pública, también en la investigación cultural y la práctica. El objetivo central es el respeto del otro. Entonces, lo "extraño" puede convertirse en una parte familiar de nosotros. El método general para lograr este objetivo, para enfrentar las trampas de la simplicidad y superar el pensamiento racial y culturalista, es hablar los unos con los otros: es mejor hablar de raza que guardar silencio sobre el racismo. Además, es más adecuado hablar de manera inclusiva sobre las culturas como facetas de la vida humana que argumentar exclusivamente sobre grietas insuperables entre culturas humanas. 


\section{Referencias bibliográficas}

Cavalli-Sforza, L. L. (1997). Genes, Peoples, and Languages. Proceedings of the National Academy of Science, 94(15), pp. 7719-7724.

Cavalli-Sforza, L. L.; P. Menozzi y A. Piazza (eds.) (1996). The History and Geography of Human Genes. Princeton: University Press.

Diamond, J. (1997). Germs, Guns and Steel. A Short History of Everybody of the Last 13.000 Years. Nueva York: Norton.

Dunn, L. C. y T. Dobzhansky (1946). Heredity, Race, and Society. Nueva York: The New American Library of World Literature, Inc.

Duster, T. (2005). Race and Reification in Science. Science, 307(5712), p. 1050.

Erikson, E. H. (1968). Identity: Youth and Crisis. Nueva York: Norton.

Erikson, J. M. y F. Stjernfelt (2009). Culturalism: Culture as Political Ideology. Eurozine [en línea], 9 de enero. Disponible en: <https://www.eurozine. com/culturalism-culture-as-political-ideology/ $>$ [acceso 7 de diciembre de 2020].

Excoffier, L. y G. Hamilton (2003). Comment on "Genetic Structure of Human Populations". Science, 300(5627), p. 1877.

Gagneux, P.; C. Wills; U. Gerloff; D. Tautz; P. A. Morin; C. Boesch; B. Fruth; G. Hohmann; O. A. Ryder y D. S. Woodruff (1999). Mitochondrial sequences show diverse evolutionary histories of African hominoids. Proceedings of the National Academy of Science, 96(9), pp. 5077-5082.

Huntington, S. P. (1996). The Clash of Civilizations and the Remaking of World Order. Nueva York: Simon \& Schuster.

Janßen, A. (1998). Vorstellungen von Menschenrassen in der Fachwissenschaft und bei Schülerinnen und Schülern. Oldenburg: Didaktisches Zentrum.

Jorde, L. B.; A. R. Rogers; M. Bamshad; W. S. Watkins; P. Krakowiak; S. Sung; J. Kere y H. C. Harpending (1997). Microsatellite Diversity and the Demographic History of Modern Humans. Proceedings of the National Academy of Science, 94(7), pp. 3100-3103.

Kattmann, U. (1980). Education against Race Prejudices as a Topic of Biology Education. En: P. J. Kelly y G. Schaefer (eds.) (1980). Biological Education for Community Development. Londres: Taylor \& Francis, pp. 159-170.

Kattmann, U. (1997). No "We” without Discriminating “They”. Internationale Schulbuchforschung, 19(2), pp. 154-156. 
Kattmann, U. (1999). Warum und mit welcher Wirkung klassifizieren Wissenschaftler Menschen? En: H. Kaupen-Haas y C. Saller (eds.) (1999). Wissenschaftlicher Rassismus. Fráncfort: Campus, pp. 65-83.

Kattmann, U. (2009). Überlegene Europäer? Ursachen unterschiedlicher Kulturentwicklung. Unterricht Biologie, 33(342), pp. 27-34.

Knußmann, R. (1996). Vergleichende Biologie des Menschen. Stuttgart: Gustav Fischer.

Lewontin, R. C. (1972). The Apportionment of Human Diversity. Evolutionary Biology, 6, pp. 391-398.

Nolting, H. P. (1987). Kein Feindbild ohne Selbstbild. En G. Sommer (ed.) (1987). Feindbilder im Dienste der Aufrüstung. Marburgo: Arbeitskreis Marburger Wissenschaftler für Friedens-und Abrüstungsforschung.

Pääbo, S. (2001). The Human Genome and our View of ourselves. Science, 291(5507), pp. 1219-1220.

Rosch, E.; C. B. Mervis; W. D. Gray; D. M. Johnson y P. Boyes-Braem (1976). Basic Objects in Natural Categories. Cognitive Psychology, 8(3), pp. 382439.

Rotimi, C. N. (2004). Are Medical and Nonmedical Uses of Large-scale Genomic Markers Conflating Genetics and 'Race'? Nature Genetics, 36(11), pp. 4347.

Royal, C. D. M. y G. M. Dunston (2004). Changing the Paradigm from 'Race' to Human Genome Variation. Nature Genetics, 36(11), pp. 5-7.

Schaefer, G. (1984). Naturwissenschaftlicher Unterricht auf dem Wege vom exklusiven zum inklusiven Denken. Der mathematische und naturwissenschaftliche Unterricht, 37(6), pp. 324-336.

Seidler, H. y A. Rett (1982). Das Reichssippenamt entscheidet. Rassenbiologie im Nationalsozialismus. Viena-Múnich: Jugend \& Volk.

Serre, D. y S. Pääbo (2004). Evidence for Gradients of Human Genetic Diversity within and among Continents. Genome Research, 14(9), pp. 1679-1685.

Stix, G. (2008). Traces of a Distant Past. Scientific American, 299(1), pp. 56-63.

Templeton, A. R. (1999). Human Races: A Genetic and Evolutionary Perspective. American Anthropologist, 101(3), pp. 632-650.

UNESCO (1995). Statement of the Scientific Workshop of the UNESCO. ConferenceAgainst Racism, Violence, and Discrimination, 8 y 9 de junio. 